\title{
Increased frequency of TAP2B in early onset pauciarticular juvenile chronic arthritis
}

\author{
R P Donn, E J Davies, P L Holt, W Thomson, W Ollier
}

\begin{abstract}
Objectives-To determine whether polymorphisms of the TAP genes, which lie within the major histocompatibility complex (MHC), are associated with juvenile chronic arthritis (JCA).

Methods-Eighty five JCA patients and 166 white controls were typed for the TAP gene alleles using ARMS-PCR. The same populations were analysed for DRB1 and DPB1 alleles using PCR-SSO typing.

Results-TAP2B was increased in early onset pauciarticular JCA (EOPA-JCA) compared with controls (62\% v 44\% Odds ratio (OR) $2 \cdot 1,95 \%$ CI $0 \cdot 9-4 \cdot 7$ ). After allowing for the known linkage disequilibrium between TAP2B and DR1 the association of TAP2B and EOPA-JCA was maintained (OR 3.5, 95\% CI 1·3-9.7). HLA-DRB1 *04 and TAP2D were found to be in linkage disequilibrium in both the control $(\Delta 0.018 \mathrm{p}<0.05)$ and JCA patient groups $(\Delta 0.021 p<0.05)$. No linkage disequilibrium was found between the TAP and DPB1 alleles.

Conclusions-The association between TAP2B and EOPA-JCA is a further indication of the heterogeneity which exists in this clinically defined subgroup of patients.
\end{abstract}

ARC/ERU,

Stopford Building,

Manchester,

United Kingdom

R P Donn

E J Davies

W Thomson

W Ollier

Rheumatic Diseases

Centre,

Clinical Sciences

Building,

Hope Hospital,

Salford,

United Kingdom

E J Davies

Department of

Rheumatology,

Stopford Building,

Stopford Build

United Kingdom

P L Holt

Correspondence to:

Dr R P Donn

ARC/ERU,

Stopford Building,

Manchester University,

Oxford Road,

Manchester M13 9PT,

United Kingdom.

Accepted for publication

28 January 1993
(Ann Rheum Dis 1994; 53: 261-264)

Juvenile chronic-arthritis (JCA) is an inflammatory arthritis starting in children under the age of sixteen years and lasting at least three months. Due to the heterogeneity of the disease a number of subgroups have been defined. Depending on the initial clinical presentation and the number of joints affected, patients with JCA are classified as having pauci or polyarticular disease onset. A further subgroup has a systemic onset with fever and rash. Of the pauciarticular onset two distinct presentations occur. Those with a later onset (after age six years) are more often male and have disease features resembling adult spondylarthropathies. The commonest JCA presentation is early onset pauciarticular (EOPA) (onset before age six years). These patients are most often female, usually anti-nuclear antibody positive and have a significant risk of developing chronic anterior uveitis. The aetiology of JCA is unknown although family studies indicate that a genetic component is involved in disease susceptibility. Studies of the major histocompatibility complex (MHC) have shown that genes of both the class I and the class II regions are associated with JCA clinical subgroups. ${ }^{1}$ In particular for the EOPA subgroup an increase in A2, DR5, DR6, DR8, $\mathrm{DPB} 1^{\star} 0201$ and certain DQA associations, that is, $\mathrm{DQA}^{\star} 0401,0501$ and 0601 have been reported. Several studies have shown that each of these HLA antigens acts independently in conferring risk in EOPA. ${ }^{2}{ }^{3}$ These HLA associations do not appear, however, to represent the entire profile of disease susceptibility in JCA, and they may be acting as markers, being in linkage disequilibrium with other susceptibility genes within the MHC.

The TAP1 and TAP2 genes have recently been mapped to the class II region of the MHC telomeric to HLA-DP. ${ }^{4}$ The products of these genes are members of the adenosine triphosphate (ATP)-binding cassette superfamily, other members of which include known transporter proteins. The products of the TAP genes are thought to form a heterodimer complex, characteristic of this superfamily, which is responsible for the transferral of processed cytoplasmic peptide fragments to the endoplasmic reticulum (ER). The heterodimer product has been localised to the membranes of the ER and cis Golgi, ${ }^{5}$ but to date no direct evidence of peptide transport has been shown.

So far human TAP1 and TAP2 genes are thought to display limited polymorphism. Colonna et $a l^{6}$ showed by single-strand conformation polymorphism two polymorphic sites within TAP1. These are an isoleucine for valine at amino acid (aa) position 333 and an aspartic acid for glycine at position 637 .

TAP2 is more polymorphic having four single aa substitution sites at aa positions 379 , 565,665 and 687. At 379 the change is isoleucine for valine and 565 is threonine for alanine. Positions 665 and 687 are in strong linkage disequilibrium. An alanine is linked with glutamine 687 whilst threonine 665 is always associated with a premature stop codon at 687. TAP1 and TAP2 alleles are assigned by the combinations of these dimorphic aa variants. $^{7}$

Polymorphisms of the TAP genes in the rat are more extreme than those recorded in humans and are functionally important, altering the identity of peptides found in association with class I molecules. ${ }^{8}$ Polymorphic variants of the human TAP genes 
might also act to influence the selection of peptides delivered to class I molecules and may disrupt the stability of the trimolecular unit formed between class I antigen, b2 microglobulin and peptide fragment. Any change to the antigen presenting complex could result in an alteration of $T$ cell response.

The TAP genes represent candidate disease susceptibility genes for JCA and they may further delineate the HLA haplotypes associated with this condition. We have therefore investigated TAP1 and TAP2 polymorphisms in different clinical subgroups of JCA.

\section{Materials and methods}

\section{PATIENTS AND CONTROLS}

Five mls of blood were taken into EDTA tubes with the consent of all patients and controls included in the study. The patient and the control populations were both from the Greater Manchester area.

Eighty five white patients conforming to the criteria or $\mathrm{JCA}^{9}$ were classified into subgroups based on the number of joints affected at disease onset plus any evidence of systemic disease features. The subgroups involved in the study were as follows: early onset pauciarticular (EOPA) $(n=29)$, $\leq$ four joints affected and onset before the age of six years. Late onset pauciarticular (LOPA) $(n=24), \leq$ four joints affected and onset after the age of six years. Polyarticular (PLY) $(n=17), \geq$ five joints affected at onset. Systemic onset (SO) $(n=17)$, pyrexia and classic Still's rash at presentation. The control population consisted of 166 randomly selected healthy UK white group.

Of our 29 EOPA-JCA patients the female to male ratio was $2: 1,41 \%$ were ANA positive and five had a history of chronic anterior uveitis. None had a family history of psoriasis. In 26 the outcome at one year was known, and of these, five had extended to polyarticular disease.

\section{DNA EXTRACTION}

Genomic DNA was extracted from whole blood using a standard, automated, phenolchloroform extraction procedure.

\section{TAP1 AND TAP2 POLYMORPHISMS}

The single base differences at aa positions 333 and 637 for TAP1 and aa positions 379565 and 665 of TAP 2 were each investigated using a combination of four primers in one reaction.

The design of the ARMS-PCR together with the primer sequences have recently been published elsewhere. $^{7}$

For each individual ARMS-PCR 0.5 ug genomic DNA was amplified in total $25 \mathrm{ul}$ reaction volume containing $200 \mathrm{uM}$ dNTPs, 1x Taq DNA polymerase buffer $(500 \mathrm{mM} \mathrm{KcL}$ $100 \mathrm{mM}$ Tris-Hcl ph8.3 $15 \mathrm{mM} \mathrm{MgCl} 2)$ and 1.5 units Taq polymerase (Advanced Biotechnologies). The amount of oligoprimer used varied from $25 \mu \mathrm{g}$ to $75 \mu \mathrm{g}$. The amplified products were separated on a $2 \%$ agarose gel stained with ethidium bromide.
HLA TYPING

The patient group and the majority of the control population were typed for DRB1 and DPB1 alleles using standard PCR-SSO methods. A proportion of controls $(n=67)$ were DRB1 typed using a Taq1 RFLP method. The individual allele frequencies are reported elsewhere. ${ }^{10}$

\section{STATISTICS}

Allele frequencies were calculated by direct counting. Delta values (linkage disequilibrium) were computed using the formulae of Mittal et $a l^{11}$

The level of statistical importance for differences in allele frequencies between patients and controls was assessed by calculating odds ratios (OR) with $95 \%$ confidence intervals $(\mathrm{CI})$. Increased risk was recorded when the $95 \%$ CI of an OR did not fall below a value of 1.0 .

\section{Results}

The gene frequencies of the TAP1 and TAP2 dimorphisms are given in table 1 . There was an increase in DG heterozygotes, with a concomitant decrease in DD homozygotes, at aa position 637 of TAP1 gene in the EOPA patients compared with controls (OR 3.2 95\% CI $1 \cdot 7-8 \cdot 2)$.

TAP1 and TAP2 allele frequencies for JCA patient subsets and controls are summarised in table 2. No differences in the frequency of TAP1 alleles were observed between controls and any JCA subgroup.

TAP2B was increased in frequency in the EOPA JCA group compared with controls $(62 \%$ v $44 \%$ ) (OR $2 \cdot 195 \%$ CI $0 \cdot 9-4 \cdot 7$ ). No other TAP2 allele frequency was increased or decreased in the JCA patient subgroups. Previous studies have demonstrated linkage disequilibrium between TAP2B and HLADR $1 .{ }^{12}$ Although the frequency of DR1 was approximately the same in EOPA JCA patients and controls $(21 \cdot 4 \%$ v $19 \cdot 8 \%)$, TAP2B frequency was re-examined in DR1 negative patients and controls. The association of TAP2B with EOPA JCA was maintained (OR $3 \cdot 595 \%$ CI $1 \cdot 3-9 \cdot 7)$.

Linkage disequilibrium existed between TAP2D and DR4 in both patients $(\Delta 0.020 \mathrm{p}$ $0.02)$ and controls $(\Delta 0.018 \mathrm{p} 0.04)$. No linkage disequilibrium was found between TAP alleles and any DPB1 alleles in either the JCA or control groups.

\section{Discussion}

The TAP genes have a role in the class I endogenous peptide processing pathway, and may also influence presentation via class II. ${ }^{13}$ Their location with the MHC could help to clarify the multiple HLA associations recorded in JCA. EOPA is the commonest presentation of JCA, and several well documented HLA antigens are known to be associated with it, which may indicate the heterogeneity within this clinically defined subgroup. 
Table $1 \%$ frequencies of TAP1 and TAP2 genes TAP1

\begin{tabular}{|c|c|c|c|c|c|c|}
\hline \multirow[t]{2}{*}{ aa Position } & \multicolumn{3}{|c|}{333} & \multicolumn{3}{|l|}{637} \\
\hline & II & $V V$ & $I V$ & $G G$ & $D D$ & $D G$ \\
\hline $\begin{array}{l}\text { EPOA }(n=28) \\
\text { LOPA }(n=21) \\
\text { PLY }(n=16) \\
\text { SO }(n=17) \\
\text { CONTROLS }(n=58)\end{array}$ & $\begin{array}{l}61 \\
76 \\
69 \\
65 \\
72\end{array}$ & $\begin{array}{l}7 \\
0 \\
0 \\
4 \\
2\end{array}$ & $\begin{array}{l}32 \\
24 \\
24 \\
31 \\
26\end{array}$ & $\begin{array}{l}0 \\
5 \\
0 \\
6 \\
0\end{array}$ & $\begin{array}{l}43 \\
67 \\
63 \\
59 \\
71\end{array}$ & $\begin{array}{l}57 \\
28 \\
37 \\
35 \\
29\end{array}$ \\
\hline
\end{tabular}

\section{TAP2}

\begin{tabular}{|c|c|c|c|c|c|c|c|c|c|}
\hline \multirow[t]{2}{*}{ aa Position } & \multicolumn{3}{|c|}{379} & \multicolumn{3}{|l|}{565} & \multicolumn{3}{|c|}{665} \\
\hline & $I I$ & $V V$ & $I V$ & $T T$ & $A A$ & $A T$ & $T T$ & $A A$ & $T A$ \\
\hline $\begin{array}{l}\text { EPOA }(n=29) \\
\text { LOPA }(n=24) \\
\text { PLY }(n=17) \\
\text { SO }(n=14) \\
\text { CONTROLS }(n=166)\end{array}$ & $\begin{array}{r}3 \\
0 \\
0 \\
7 \\
41\end{array}$ & $\begin{array}{l}73 \\
61 \\
71 \\
86 \\
81\end{array}$ & $\begin{array}{r}24 \\
39 \\
29 \\
7 \\
15\end{array}$ & $\begin{array}{l}0 \\
0 \\
0 \\
7 \\
1\end{array}$ & $\begin{array}{l}83 \\
72 \\
82 \\
79 \\
84\end{array}$ & $\begin{array}{l}17 \\
28 \\
18 \\
14 \\
15\end{array}$ & $\begin{array}{l}41 \\
44 \\
47 \\
64 \\
55\end{array}$ & $\begin{array}{r}7 \\
12 \\
6 \\
7 \\
5\end{array}$ & $\begin{array}{l}52 \\
44 \\
47 \\
29 \\
40\end{array}$ \\
\hline
\end{tabular}

aa = amino acid $\quad \mathrm{I}=$ Isoleucine; $\mathrm{V}=$ Valine; $\mathrm{G}=$ Glycine; $\mathrm{D}=$ Aspartic acid; $\mathrm{A}=$ Alanine; $\mathrm{T}=$ Threonine.

Table 2 Allele frequencies \%

TAP1

\begin{tabular}{llllll}
\hline Allele & $\begin{array}{l}\text { EOPA } \\
(n=28)\end{array}$ & $\begin{array}{l}\text { LOPA } \\
(n=21)\end{array}$ & $\begin{array}{l}P L Y \\
(n=16)\end{array}$ & $\begin{array}{l}\text { SO } \\
(n=17)\end{array}$ & $\begin{array}{l}\text { CONTROLS } \\
(n=58)\end{array}$ \\
\hline (A) & 61 & 76 & 81 & 65 & 76 \\
$(\mathrm{~B})$ & 7 & 0 & 0 & 12 & 0 \\
$(\mathrm{C})$ & 7 & 5 & 13 & 12 & 5 \\
$(\mathrm{D})$ & 18 & 14 & 19 & 12 & 5 \\
$\star{ }^{(\mathrm{AB} / \mathrm{CD})}$ & 32 & 19 & 19 & 18 & $24]$ \\
\hline
\end{tabular}

\begin{tabular}{llllll} 
TAP2 & \multicolumn{1}{l}{} \\
\hline Allele & $\begin{array}{l}\text { EOPA } \\
(n=29)\end{array}$ & $\begin{array}{l}\text { LOPA } \\
(n=24)\end{array}$ & $\begin{array}{l}P L Y \\
(n=17)\end{array}$ & $\begin{array}{l}\text { SO } \\
(n=14)\end{array}$ & $\begin{array}{l}\text { CONTROLS } \\
(n=166)\end{array}$ \\
\hline (A) & 70 & 83 & 82 & 79 & 82 \\
(B) & 62 & 46 & 53 & 36 & 44 \\
(C) & 10 & 13 & 12 & 7 & 11 \\
(D) & 18 & 21 & 18 & 7 & 15 \\
(E) & 3 & 4 & 0 & 14 & 6 \\
(H) & 3 & 0 & 0 & 0 & 1
\end{tabular}

*Allele status can not be assigned, family studies required to establish pattern of segregation. Explanation of Alleles: Alleles (A-D TAP1; A-H TAP2) are derived from the combination of the aa changes at the key polymorphic positions ie 333 and 637 for TAP1 and 379565665 for TAP2.

$\begin{array}{lll}\text { TAP1 } & \text { TAP2 } & \\ \text { A IA } & \text { A VAT } & \text { EVTT } \\ \text { B VG } & \text { B VAA } & \text { H IAA }\end{array}$

B VG B VAA H IAA

D IAT pauciarticular JCA patients. They reported an increase in TAP1B2 and in TAP2B, but suggest the findings are secondary to linkage disequilibrium between the TAP alleles and $\mathrm{DRB} 1{ }^{\star} 0801$ and $\mathrm{DPB} 1{ }^{\star} 0201$. Of our control population $5 \%$ were DR 8 and $15 \%$ were $\mathrm{DPB} 1^{\star} 0201$. No linkage disequilibrium between DR8 and TAP2B or DPB1*0201 and TAP2B was found in our population.

There was difficulty in assigning TAP1 alleles to all patients in our study, as those typing heterozygous (isoleucine/valine) at aa position 333 and heterozygous (aspartic acid/ glycine) at aa position 637 could be either TAP1A/TAP1B or TAP1C/TAP1D. Based on the individual allele frequencies these individuals will most likely be TAP1A/TAP1B, and we are currently examining families to establish the pattern of segregation. From the gene frequencies in our JCA patient population, however, there is no increase in valine/valine homozygotes (aa 333)/glycine/glycine homozygotes (aa 637) compared with controls.

In conclusion, it would appear that the increase in TAP2B represents another association with EOPA JCA, not due to linkage disequilibrium with DRB1 or DPB1 alleles. This, together with the many other HLA antigens known to confer risk in EOPA, reinforces the apparent heterogeneity of this JCA subgroup. EOPA might itself be several disease entities with no unifying aetiology. It may be useful to look further at the TAP gene associations, both in larger numbers of ANA positive uveitis cases and in those EOPA patients which extend to polyarticular disease. Whilst the entire classification of JCA remains a difficult and controversial area it could be that the evolving immunogenetic profile of EOPA will help in the appraisal of the current clinically derived subgrouping.

We thank A Payton and L Pepper for their technical assistance, and $\mathrm{P}$ Brennan for his statistical advice. We are grateful also to The Arthritis and Rheumatism Council for their financial support.

1 Nepom B S, Glass D N. Juvenile rheumatoid arthritis and HLA: report of the Park City III workshop. $\mathcal{f}$ Rheum 1992; 19 (suppl 33): 70-4.

We have now found a weak association between TAP2B and EOPA. In a previously reported smaller number of the same population of EOPA JCA patients, the trend towards an increase in TAP2B was present. ${ }^{14}$ TAP2B has been shown to be in strong linkage disequilibrium with DR1. ${ }^{12}$ Whilst DR1 is raised in LOPA it is not found at an increased frequency in EOPA. As expected therefore after analysing DR1 negative EOPA patients and controls, the increase in TAP2B was found not to be dependent on any linkage disequilibrium with DR1.

The TAP genes were not found to be raised or lowered in any other JCA subgroup. The only positive linkage disequilibrium found was that between DR4 and TAP2D, occurring in both the JCA and control populations. ${ }^{12}$

Ploski et al ${ }^{15}$ used a PCR-RFLP method to determine A, B and C phenotypes of the TAP1 and TAP2 genes. By this method they showed an increased frequency of TAP1B in JCA patients. Fernandez-Vina $e t$ al ${ }^{16}$ used SSOP to look at TAP1 and TAP2 in persistently

Morling N, Friis J, Fugger L, et al. DNA polymorphism of HLA class II genes in pauciarticular juvenile rheumatoid arthritis. Tiss Antigens 1991; 38: 16-23.

3 Paul C, Schoenwald U, Truckenbrodt $\mathrm{H}$, et al. HLA-DP/ DR interaction in early onset pauciarticular juvenile chronic arthritis. Immunogenetics 1993; 37: 442-8.

4 Powis S H, Mockridge I, Kelly A, et al. Polymorphism in a second $\mathrm{ABC}$ transporter gene located within the class II region of the human major histocompatibility complex. Proc Natl Acad Sci USA 1992; 89: 1463-7.

5 Kleijmeer M J, Kelly A, Geuze H J, Slot J W, Townsend A, Trowsdale $T$. Location of MHC-encoded transporters in the endoplasmic reticulum and cis-Golgi. Nature 1992; 357: 342-4.

6 Colonna M, Bresnahan M, Bahram S, Strominger JL, Spies $\mathrm{T}$. Allelic variants of the human putative peptide transporter involved in antigen processing. Proc Natl Acad Sci USA 1992; 89: 3932-6.

7 Powis S H, Tonks S, Mockridge I, Kelly A P, Bodmer J G, Trowsdale J. Alleles and haplotypes of the MHC-encoded ABC transporters TAP1 and TAP2. Immunogenetics 1993; 37: 373-80.

8 Powis S J, Deverson E V, Coadwell W J, et al. Effect of polymorphism of an MHC-linked transporter on the peptides assembled in a class I molecule. Nature 1992; 357: 211-5.

9 Wood P H N. Special meeting on: Nomenclature and classification of arthritis in children. In: Munthie E, ed. The care of rheumatic children. Basle: EULAR, 1978: 47 .

10 Donn R P, Pepper L, Carthy D, Holt L, Ollier W. Thomson W. ANA antibodies in Early Onset Pauciarticular JCA are associated with HLA-DPB ${ }^{\star} 0201$ and DRB1 1 1301: A possible JCA associated haplotype (Submitted). 
11 Mittal K K, Hasegawa T, Ting H, Mickey M R, Terasaki P I. Genetic variation in the HIA system between Ainus, Japanese and Caucasians. In: Dausset J, Colombani J, eds. Histocompatibility Testing 1972. Copenhagen: Munksgaard, 1973: 187-95.

12 Donn R P Davies E J. Thomson W, Hillarby M C, Ollier W R R DAP J, Thomson W, Hillarby M C, Olier European Journal of Immunogenetics (In Press).

13 Mainati M S, Marti M, LaVaute T, et al. Processing pathways for presentation of cytosolic antigen to MHC class II-restricted T cells. Nature 1992; 357: 702-4.
14 Donn R, Ollier W E R, Powis S H, Holt L, Thomson W. Lack of association between TAP2 gene polymorphisms and juvenile chronic arthritis. Clin Exp Rheum 1993; 11 (suppl 9): 75 .

15 Ploski R, Undlien D E, Vinje O, Forre O, Thoresby E, Ronnigen K S. Polymorphism of peptide transporter genes and susceptibility to juvenile rheumatoid arthritis JCA). Clin Exp Rheum 1993; 11 (suppl 9): 74 .

16 Fernandez-Vina M A, Fink C W, Sang S, Stastny P. Peptide transporter genes in susceptibility to juvenile arthritis. Human Immunology 1993; 37 (suppl 1): 58. 